\title{
Unimolecular Decay of the Dimethyl-Substituted Criegee Intermediate in Alkene Ozonolysis : Decay Time Scales and the Importance of Tunneling
}

\section{Drozd, Greg T.}

2017-08-17

Drozd , G T , Kurten , T , Donahue , N M \& Lester , M I 2017 , ' Unimolecular Decay of the Dimethyl-Substituted Criegee Intermediate in Alkene Ozonolysis : Decay Time Scales and the Importance of Tunneling ' , Journal of Physical Chemistry A, vol. 121, no. 32 , pp. 6036-6045 . https://doi.org/10.1021/acs.jpca.7b05495

http://hdl.handle.net/10138/318333

https://doi.org/10.1021/acs.jpca.7b05495

unspecified

acceptedVersion

Downloaded from Helda, University of Helsinki institutional repository.

This is an electronic reprint of the original article.

This reprint may differ from the original in pagination and typographic detail.

Please cite the original version. 


\title{
Unimolecular decay of the dimethyl substituted Criegee in- termediate in alkene ozonolysis: Decay timescales and the importance of tunneling
}

\author{
Greg t. Drozd $\dagger$ \\ Theo Kurtén $\ddagger$ \\ Neil M. Donahue§ \\ Marsha I. Lester†* \\ †Department of Chemistry, University of Pennsylvania, Philadelphia, Pennsylvania 19104-6323, USA \\ ¥Department of Chemistry, PO Box 55, 00014 University of Helsinki, Finland \\ $\S$ Department of Chemistry, Carnegie Mellon University, Pittsburgh, Pennsylvania 15123, USA
}

\begin{abstract}
We used the steady-state master equation to model unimolecular decay of the Criegee intermediate formed from ozonolysis of 2,3-dimethyl-2-butene (tetramethyl ethylene, TME). Our results show the relative importance and timescales for both the prompt and thermal unimolecular decay of the dimethyl-substituted Criegee intermediate, $\left(\mathrm{CH}_{3}\right)_{2} \mathrm{COO}$. Calculated reactive fluxes show the importance of quantum mechanical tunneling for both prompt and thermal decay to $\mathrm{OH}$ radical products. We determined the initial energy distribution of chemically activated $\left(\mathrm{CH}_{3}\right)_{2} \mathrm{COO}$ formed in TME ozonolysis by combining microcanonical rates $\mathrm{k}(\mathrm{E})$ measured experimentally under collision free conditions and modeled using semi-classical transition-state theory (SCTST) with pressure-dependent yields of stabilized Criegee intermediates measured with scavengers in flow-tube experiments. Thermal decay rates under atmospheric conditions $\mathrm{k}(298 \mathrm{~K}, 1 \mathrm{~atm})$ increase by more than an order of magnitude when including tunneling. Accounting for tunneling has important consequences for interpreting pressure dependent yields of stabilized Criegee intermediates, particularly with regard to the fraction of Criegee intermediates formed in the zero-pressure limit.
\end{abstract}

\section{Introduction}

Alkene ozonolysis is a major oxidation reaction in the atmosphere; it affects the loss of biogenic and anthropogenic compounds, provides a significant source of hydroxyl radical $(\mathrm{OH})$, particularly during night, and creates products that may form particulate matter. ${ }^{-4}$ A key step in the alkene ozonolysis reaction is formation of a carbonyl oxide, or Criegee intermediate, and the fate of the Criegee intermediate is the single most important step in ozonolysis for determining the effect of alkene ozonolysis on the atmosphere. While there are numerous potential fates for Criegee intermediates, they can be broadly separated into two classes, unimolecular decay and bimolecular reaction. Unimolecular decay most directly leads to $\mathrm{OH}$ formation, impacting atmospheric radical budgets. Bimolecular reaction can lead to formation of low volatility products that control formation and growth rates of new particles and hence cloud formation. 5,6 The branching between these two pathways is critical in predicting the effects of alkene ozonolysis on the atmosphere.

A key aspect in determining the branching between unimolecular decay and bimolecular reaction is the stabilization of the Criegee intermediate after its formation. Alkene ozonolysis begins with ozone adding across an alkene 
double bond to form a primary ozonide (POZ). This cycloaddition is highly exothermic, so the POZ rapidly decomposes into the Criegee intermediate and a carbonyl coproduct (CCP), both of which have high chemical activation. Criegee intermediates dissipate this excess energy arising from chemical activation through collisional energy transfer with bath-gas molecules $\left(\mathrm{N}_{2}\right.$ and $\mathrm{O}_{2}$ in air) to reach thermal equilibrium. The process of thermalization is pressure dependent, but at $1 \mathrm{~atm}$, where the collision frequency is approximately $10 \mathrm{~ns}^{-1}(\mathrm{GHz})$, it takes place on timescales of tens of nanoseconds, setting up a competition between stabilization of Criegee intermediates and unimolecular decay to $\mathrm{OH}$ products. Consequently, a fraction of the energized Criegee intermediates will undergo prompt unimolecular decay and the remainder will become stabilized Criegee intermediates prior to thermal decay to $\mathrm{OH}$ products. ${ }^{12,7-11}$

Stabilized Criegee intermediate formation is the first critical branching point in determining atmospheric effects of alkene ozonolysis. The second critical branching point is the fate of the Criegee intermediates once they are stabilized, which may involve thermal unimolecular decay of stabilized Criegee intermediates or bimolecular reactions. Thus, the overall branching between unimolecular decay and bimolecular reaction of Criegee intermediates depends on (1) the competition between collisional stabilization and prompt unimolecular decay at chemically activated energies and (2) the competition between thermal unimolecular decay and bimolecular reaction at thermal energies.

There are two pathways available for unimolecular decay of Criegee intermediates, and they depend on the conformation of the Criegee intermediate, namely whether the terminal oxygen of the Criegee intermediate faces a carbon with an $\alpha$-hydrogen atom (syn) or does not (anti). $\mathrm{CH}_{2} \mathrm{OO}$ would formally be included as an anti-conformer. A high barrier prevents interconversion between syn- and anti-conformers of Criegee intermediates. ${ }^{2}$ syn-Criegee intermediates isomerize to a vinyl hydroperoxide (VHP) through a 1,4-hydrogen transfer with a five-membered cyclic transition state. The VHP formed is also chemically activated and decomposes to vinoxy and $\mathrm{OH}$ radicals. anti-Criegee intermediates mainly proceed through a three-member ring closure to form a dioxirane intermediate and subsequently to a more complex array of products, which may also include $\mathrm{OH}$ at relatively small yields. ${ }^{13-17}$ Unimolecular decay of syn-Criegee intermediates forms $\mathrm{OH}$ with nearly unit yield. 2,3-dimethyl-2-butene (tetramethyl ethylene, TME) ozonolysis gives $\mathrm{OH}$ with a 0.9 yield, and for other alkenes, like 2-Butene, ozonolysis will generate $\mathrm{CH} 3 \mathrm{CHOO}$, and the $\mathrm{OH}$ yield is only 0.33 (Z-2-Butene) and 0.64 (E-2-Butene). ${ }^{13,18}$ The pathway a Criegee intermediate follows and the products formed will thus depend on the Criegee intermediate conformation and energy relative to the transition states for the available pathways, which govern the rate of unimolecular decay.

Bimolecular reactions of stabilized Criegee intermediates with key atmospheric species, including water vapor and $\mathrm{SO}_{2}$, have now been directly investigated using a number of measurement techniques. ${ }^{19-24}$ These observations have been possible over the last several years using a novel method to produce Criegee intermediates from di-iodo alkane precursors. ${ }^{19}$ Many of these bimolecular reactions of Criegee intermediates have low energetic barriers, allowing reaction of thermalized Criegee intermediates. ${ }^{25-27}$ Currently, reaction of stabilized Criegee intermediates with sulfur dioxide $\left(\mathrm{SO}_{2}\right)$ and water or water dimer are believed to be most atmospherically relevant. 19,20,22-26,28-33 The reaction of stabilized Criegee intermediates with water dimer, $\left(\mathrm{H}_{2} \mathrm{O}\right)_{2}$, forms stable hydroyxyhydroperoxides. ${ }^{34}$ Stabilized Criegee interme- 
diates can oxidize $\mathrm{SO}_{2}$ to form $\mathrm{SO}_{3}$, which then reacts with ambient water vapor to form sulfuric acid. These bimolecular reactions are predicted to have a strong dependence on stabilized Criegee intermediate conformation. For anti-stabilized Criegee intermediates, reaction with $\mathrm{SO}_{2}, \mathrm{H}_{2} \mathrm{O},\left(\mathrm{H}_{2} \mathrm{O}\right)_{2}$, and also formic acid, $\mathrm{HCOOH}$, may contribute significantly to their overall decay. 22,30-32 For syn-stabilized Criegee intermediates, reaction with $\mathrm{SO}_{2}$ and $\left(\mathrm{H}_{2} \mathrm{O}\right)_{2}$ may be competitive with thermal unimolecular decay, although at atmospheric concentrations, thermal unimolecular decay is expected to be the dominant fate for synstabilized Criegee intermediates. ${ }^{20,24,25,29,35-37}$ Even as minor channels, these bimolecular reactions can have important effects on the atmosphere, such as enhancing particle nucleation rates. 38,39

The competition between unimolecular decay and bimolecular reaction of Criegee intermediates depends on the relative rates for all the involved processes over a wide range of Criegee intermediate energies. We focus here on the reactivity of $\left(\mathrm{CH}_{3}\right)_{2} \mathrm{COO}$, a prototypical syn-Criegee intermediate with a known (near unity) $\mathrm{OH}$ yield and available experimental evidence on unimolecular decay. ${ }^{111}, 20,25,36,40-42$ The rate of unimolecular decay of $\left(\mathrm{CH}_{3}\right)_{2} \mathrm{COO}$ to $\mathrm{OH}$ products is strongly energy dependent, with microcanonical $k(E)$ varying by many orders of magnitude (more than 7) over the range of Criegee intermediate energies involved in ozonolysis reactions. ${ }^{36,42}$ This wide range of unimolecular decay rates is due to the exothermicity of ozonolysis, which leads to Criegee intermediates with a distribution of energies that extends well above and below the computed barrier for $\mathrm{H}$-atom transfer from Criegee intermediate to VHP and resultant decay to $\mathrm{OH}$ products. At high energies ( $\mathrm{E}$ $\left.>9000 \mathrm{~cm}^{-1}\right) \mathrm{k}(\mathrm{E})$ are fast enough $\left(>10^{9} \mathrm{sec}^{-1}\right)$ such that unimolecular decay occurs on subnanosecond timescales and thus competes with collisional stabilization, which occurs on a timescale of tens of nanoseconds at 1atm. At lower energies $\left(E<5000 \mathrm{~cm}^{-1}\right)$, stabilized Criegee intermediates will become thermalized and undergo unimolecular decay on a longer timescale of milliseconds, ca. $3 \mathrm{~ms}$ at $298 \mathrm{~K}$ in high pressure limit at $298 \mathrm{~K}$, which is slow enough for competition from bimolecular reaction. ${ }^{20,25,36,42,43}$ For example, the timescales for reaction with $\mathrm{SO}_{2}$ and $\left(\mathrm{H}_{2} \mathrm{O}\right)_{2}$ with syn-stabilized Criegee intermediates have been estimated to occur on 5-10 ms timescales for realistic concentrations of these reactants in the atmosphere. ${ }^{20,24,25,29,31}$

Unimolecular decay of syn-Criegee intermediates occurs through a 1,4-hydrogen shift, forming a VHP that leads to $\mathrm{OH}$ products. Because $\mathrm{H}$-atom transfer is involved, quantum mechanical tunneling can play an important role in unimolecular decay at energies in the vicinity of and below the barrier to unimolecular decay. ${ }^{35-37,42,44-47}$ It is clear that understanding both the energy distribution of Criegee intermediates formed in alkene ozonolysis and accurate $\mathrm{k}(\mathrm{E})$ over the range of Criegee intermediate internal energies from the zero-point energy up to more than 10,000 $\mathrm{cm}^{-1}$ are required to determine the branching between unimolecular decay of Criegee intermediates and bimolecular reaction.

In this work, we present steady-state master equation modeling that captures the dynamics of the dimethyl-substituted Criegee intermediate, $\left(\mathrm{CH}_{3}\right)_{2} \mathrm{COO}$, formed from ozonolysis of TME. Our results give new insight into both the prompt and thermal unimolecular decay of the dimethyl-substituted Criegee intermediate. Calculated reactive fluxes show the importance of quantum mechanical tunneling to prompt and thermal decay to $\mathrm{OH}$ products. We constrain the initial energy distribution of $\left(\mathrm{CH}_{3}\right)_{2} \mathrm{COO}$ by combining microcanonical rates $\mathrm{k}(\mathrm{E})$ modeled using semiclassical transition-state theory (SCTST) with pressure dependent yields of stabilized Criegee intermediates measured in flow tube 
scavenging experiments. The modeled $\mathrm{k}(\mathrm{E})$ are experimentally verified by energydependent measurements of $\mathrm{k}(\mathrm{E})$. $^{36,42}$ We provide further interpretation of the pressuredependent yields of stabilized Criegee intermediates, particularly with regard to the fraction of stabilized Criegee intermediates formed in the zero-pressure limit. Thermal decay rates $\mathrm{k}(\mathrm{T})$ are shown to increase by more than an order of magnitude when including tunneling.

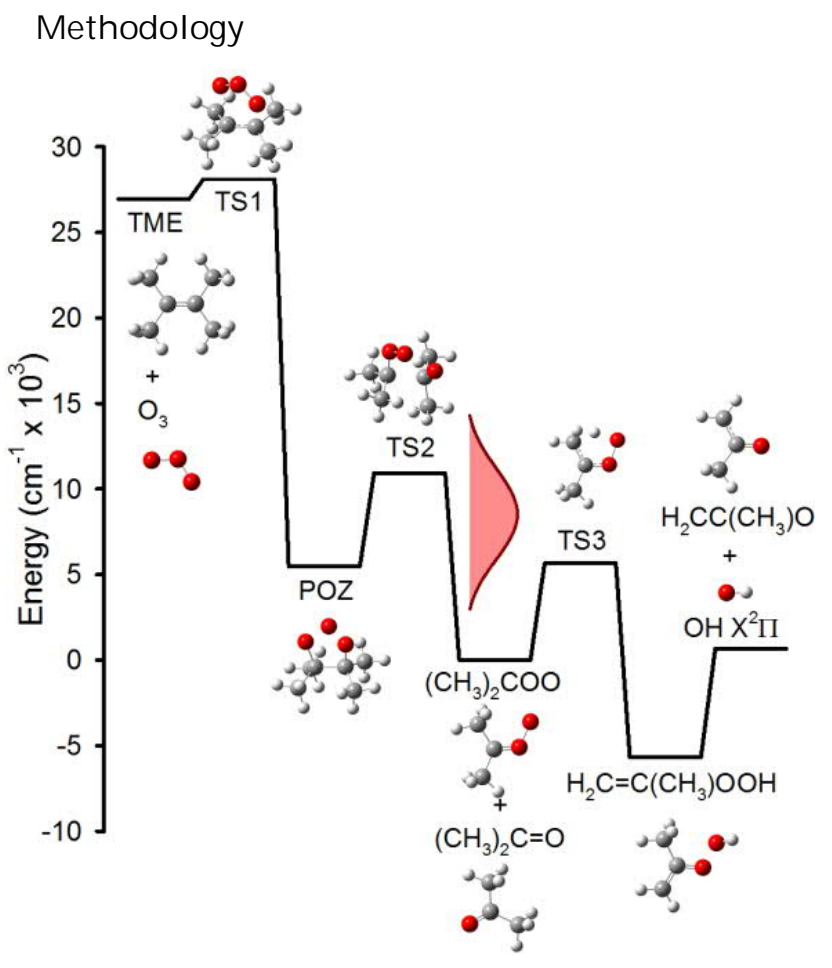

Figure 1 Reaction pathway for ozonolysis of TME via the $\left(\mathrm{CH}_{3}\right)_{2} \mathrm{COO}$ Criegee intermediate to $\mathrm{OH}$ products. $\mathrm{POZ}$ formation is exothermic, and decomposition forms $\left(\mathrm{CH}_{3}\right)_{2} \mathrm{COO}$ and $\left(\mathrm{CH}_{3}\right)_{2} \mathrm{C}=\mathrm{O}$ products that are highly activated. The activated $\left(\mathrm{CH}_{3}\right)_{2} \mathrm{COO}$ (depicted in red) proceeds along a 14-hydrogen transfer pathway to 1 methylethenylhydroperoxide $\left(\mathrm{H}_{2} \mathrm{C}=\mathrm{C}\left(\mathrm{CH}_{3}\right) \mathrm{OOH}\right)$ via a transition state (TS3), followed by dissociation to $\mathrm{OH}+1$-methylethenyloxy $\left(\mathrm{H}_{2} \mathrm{CC}\left(\mathrm{CH}_{3}\right) \mathrm{O}\right)$ products. A portion of Criegee intermediates decays promptly to $\mathrm{OH}$ products, while the balance is collisionally stabilized prior to thermal decay to $\mathrm{OH}$ products.

\section{Quantum Mechanical Calculations}

Master-equation modeling requires detailed information on the energies, structures, and vibrational frequencies of key stationary points along the reaction pathway. The reac- tion coordinate for the ozonolysis of TME is shown in Figure 1and includes the energy distribution of the chemically activated $\left(\mathrm{CH}_{3}\right)_{2} \mathrm{COO}$ Criegee Intermediate. The reaction pathway starts with formation and decomposition of the primary ozonide (POZ) to form the Criegee intermediate and the carbonyl co-product (CCP, acetone). The Criegee intermediate then undergoes a 1,4 H-shift and isomerization to form a vinyl hydroperoxide (VHP). Because VHP rapidly decomposes to form $\mathrm{OH}$ and vinoxy radicals, the 1,4 $\mathrm{H}$-atom transfer isomerization of the Criegee intermediate is simply referred to as unimolecular decay.

The initial energy distribution of the chemically activated Criegee intermediate energy depends on the exothermicity of POZ decomposition and the partitioning of energy among the two products, the Criegee intermediate and the CCP. We estimated the total energy released during POZ decomposition using abinitio calculations. We based our initial estimate of the barrier separating reactants from POZ (TS1) on literature values. ${ }^{1,48}$ Initial geometry optimization for other stationary points utilized B3LYP/6-31+G(d) method/basis calculation on all conformers using the Spartan ' 14 program. ${ }^{49}$ We then optimized the lowest-energy structures at the wb97xd/aug-cc-pVTZ level using the Gaussian 09 program suite with the ultrafine integration grid. ${ }^{50}$ Finally, we calculated single-point energies for these optimized structures at the CCSD(T)-FI2a/VDZ-F12 level of theory using the Molpro program suite. ${ }^{51}$ For Criegee intermediate unimolecular decay, we adopted the energies of the Criegee intermediate and the transition state to the VHP (TS3) from Fang et al. ${ }^{36}$ These calculations utilized energies at the CCSD(T)-F12 level of theory in the complete basis set (CBS) limit. Additional corrections to the Criegee intermediate and VHP single-point energies included: anharmonic zero-point energy, higher order excitations, 
core-valence interactions, relativistic effects, and diagonal Born-Oppenheimer corrections.

Normal-mode vibrational frequencies are needed to calculate the sums and densities of states for both the partitioning of the POZ decomposition energy between the CCP and Criegee intermediate and for RRKM calculations of microcanonical rate constants for Criegee intermediate unimolecular decay. For the partitioning of the POZ decomposition energy, we calculated the CCP and Criegee intermediate harmonic vibrational frequencies using wb97xd/aug-cc-pVTZ calculations. For RRKM calculations, we used the vibrational frequencies with anharmonicities of the Criegee intermediate and TS3 calculated by Fang et al. with second-order vibrational perturbation theory (VPT2) with B2PLYPD3/ccpVTZ ${ }^{36}$

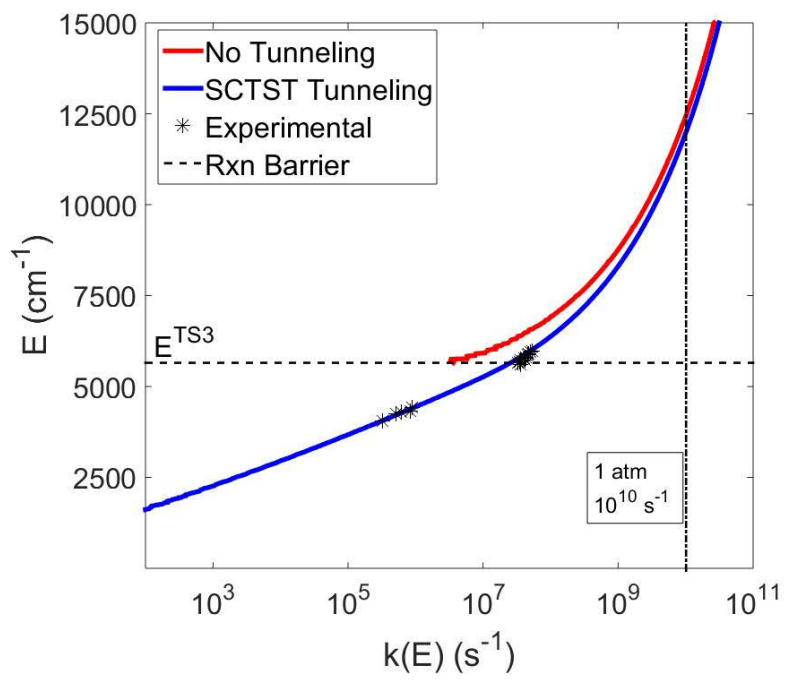

Figure 2 Unimolecular decay rate constants $\mathrm{k}(\mathrm{E})$ for $\left(\mathrm{CH}_{3}\right)_{2} \mathrm{COO}$ to $\mathrm{OH}$ products measured experimentally (asterisks) at specific energies in the $3900-4600$ and $5600-6000 \mathrm{~cm}^{-}$ ${ }^{1}$ regions. ${ }^{36,42}$ Also shown are statistical RRKM rate constants $\mathrm{k}(\mathrm{E})$ computed in the energy range of $2000-15000 \mathrm{~cm}^{-1}$ using semi-classical transition state theory (SCTST) for tunneling (blue) or without tunneling (red). ${ }^{36,42,52-54}$ Tunneling always increases $\mathrm{k}(\mathrm{E})$ and occurs through the reaction barrier (TS3) associated with 1,4 hydrogen transfer from the syn-methyl group to terminal O-atom of $\left(\mathrm{CH}_{3}\right)_{2} \mathrm{COO}$, which leads to $\mathrm{OH}$ products. A barrier of $16.2 \mathrm{kcal} \mathrm{mol}^{-1}\left(5650 \mathrm{~cm}^{-1}\right)$ is derived from high-level ab initio calculations including zero-point and other corrections. ${ }^{36}$

\section{Microcanonical Rate Constants}

We calculate the microcanonical rate constants for Criegee intermediate isomerization to the VHP (unimolecular decay) using RiceRamsperger-Kassel-Marcus (RRKM) theory:

$$
k(E)=\frac{\sigma_{\text {eff }}}{\sigma_{\text {eff }}^{\ddagger}} \frac{G\left(E-E_{0}\right)}{h \rho(E)}
$$

where $\sigma_{\text {eff }}$ is the effective symmetry of the reactant Criegee intermediate (1), $\sigma_{\text {eff }}^{\ddagger}$ is the effective symmetry for the transition state (1/2), $h$ is Planck's constant, $G\left(E-E_{0}\right)$ is the sum of states at transition state TS3, ${ }^{36,42} \mathrm{E}_{0}$ is the energy of the computed barrier height $\mathrm{TS}_{3}$ $\left(5650 \mathrm{~cm}^{-1}, 16.2 \mathrm{kcal} \mathrm{mol}^{-1}\right)$ for $\mathrm{H}$-atom transfer to form the VHP, and $\rho$ (E) is the density of states for the reactant at energy E. ${ }^{36,42} \mathrm{We}$ treated tunneling by calculating the effective sum of states at TS3 using the semi-classical transition-state theory (SCTST) of Miller et al., as implemented in the SCTST program of the MULTIWELL program suite. ${ }^{52-54}$ We calculated the density of states for the reactant Criegee intermediate using the DENSUM program of the MULTIWELL program suite. ${ }^{52}$ We show the calculated rate constants along with measurements in Figure 2, displaying close agreement. Note also that tunneling consistently always increases the microcanonical rates, and the SCTST-tunneling values (blue) are always greater than the notunneling case (red). For example, at $6500 \mathrm{~cm}^{-}$ ${ }^{1}$ with tunneling the rate is $1 \times 10^{8} \mathrm{~s}^{-1}$, and without tunneling the rate is $4 \times 10^{7} \mathrm{~s}^{-1}$.

\section{Criegee Intermediate Initial Energy Distribution}

We calculate the energy distribution of the Criegee intermediate following ozonolysis using a statistical partitioning of the total energy available to products following POZ decomposition:

$$
p\left(E, E_{T o t}\right)=\frac{\rho(E) G\left(E_{t o t}-E\right)}{\int_{0}^{E_{T}} \rho\left(E^{\prime}\right) G\left(E_{t o t}-E^{\prime}\right) d E^{\prime}}
$$

where $\rho$ is the density of states of the Criegee intermediate, $G$ is the sum of states of the CCP, and $E_{\text {tot }}$ is the total energy available to 
the system. ${ }^{55}$ This approach has been used in previous treatments of alkene ozonolysis and shown to be valid for similar size systems. ${ }^{7,16,44,56,57}$ We calculated the sums and densities of states for the Criegee intermediate and the CCP using the DENSUM program of the MULTIWELL program suite. ${ }^{52}$ The minimum total available energy following $\mathrm{POZ}$ decomposition is the difference in the energy of TS1 $\left(27350 \mathrm{~cm}^{-1}, 80.4 \mathrm{kcal} \mathrm{mol}^{-1}\right)$ and TS2 $\left(10900 \mathrm{~cm}^{-1}, 31.2 \mathrm{kcal} \mathrm{mol}^{-1}\right)$. This assumes the potential energy associated with the TS2 barnier flows into translational recoil of the fragments. ${ }^{14,44,56,57}$ The geometry of TS2 is nonplanar, whereas the products are both planar, and this change in geometry will result in additional internal excitation of the products, thereby increasing the total available energy to fragments beyond the minimal energy assumption. Some fraction of the potential enengy released after crossing the TS2 barrier, equal to the reverse barrier energy $\left(10900 \mathrm{~cm}^{-}\right.$ $\left.{ }^{1}\right)$, will thus also be part of the total available energy. As discussed below, an additional 2300 $\mathrm{Cm}^{-1}$ is added to match experimental results. We calculated Etrans using a prior distribution calculation employing the sum of states for the Criegee intermediate and CCP. ${ }^{58,59}$

\section{Master Equation Calculations}

We used the one-dimensional master equation to calculate the statistical reaction dynamics of the dimethyl Criegee intermediate, $\left(\mathrm{CH}_{3}\right)_{2} \mathrm{COO}$. The master equation describes the time- and energydependent population, $N(E, t)$, of Criegee intermediates undergoing collisional stabilization and unimolecular decay:

$\frac{d N}{d t}=r F-[\omega(\mathbf{I}-\mathbf{P})+\mathbf{K}] N$

where $r$ is the overall rate of formation of the intermediate species, $\mathrm{F}$ is the normalized vibrational population of the nascent reactants, $\omega$ is the collisional frequency, $\mathbf{I}$ is the unit matrix, $\mathbf{P}$ is the normalized energy transfer matrix, and $\mathbf{K}$ is the diagonal matrix of microca- nonical rate constants for unimolecular decay. $7,48,60,61$ The solution to Equation 3 can be expressed as:

$N(t)=\mathbf{U L U}^{-1} F$

where $\mathrm{U}$ is the corresponding eigenvector matrix of $\mathrm{J}$, and $\mathrm{L}$ is a diagonal matrix with elements $\mathrm{L}_{\mathrm{i}}=\left(1 \exp \left(-\lambda_{\mathrm{i}} \mathrm{t}\right)\right) / \lambda_{\mathrm{i}}{ }^{62}$ The values $\lambda_{\mathrm{i}}$ are the eigenvalues of $J$ and the rates for processes affecting the corresponding eigenvectors, or distributions of the total population as a function of energy. We used an energy grain size of $10 \mathrm{~cm}^{-1}$, similar to that of Kuwata et al. ${ }^{44} \mathrm{We}$ used an average energy transfer per collision $\left\langle E_{\text {Down }}\right\rangle$ of $250 \mathrm{~cm}^{-1}$, similar to the majority of previous calculations. ${ }^{1,16,28,29,44}$ The previous calculations of Kroll et al. and Chuong et al. used a higher $\left\langle E_{\text {Down }}\right\rangle$ of $500 \mathrm{~cm}^{-17,48}$ Calculations probing the sensitivity of our results to $\left\langle E_{\text {Down }}\right\rangle$ show that the pressure dependent yields of stabilized Criegee intermediates may also be fit with $\left\langle E_{\text {Down }}\right\rangle=500 \mathrm{~cm}^{-1}$ and partitioning $3600 \mathrm{~cm}^{-1}$ of the potential energy released after crossing the TS2 barrier to the total available energy of the product fragments. We solved the master equation via matrix inversion, using a Matlab-based code developed at Carnegie Mellon University. ${ }^{48,61}$

There are two types of processes for the system under consideration, collisional energy transfer (leading to the thermal energy distribution) and reactive loss (unimolecular decay of the Criegee intermediate). Collisional energy transfer in the master equation is defined by the energy transfer matrix $\mathbf{P}$. Downward collisions are described by elements, $\mathbf{P}_{\mathrm{ij}}$, giving the probability that a molecule at energy $E_{j}$ will transfer down to energy $\mathrm{E}_{\mathrm{i}}$ after a collision. These probabilities are modeled as:

$$
\boldsymbol{P}_{i j} \propto\left(\frac{\rho\left(E_{j}\right)}{\rho\left(E_{i}\right)}\right) \exp \left(\frac{-\left(E_{j}-E_{i}\right)}{\left\langle E_{\text {Down }}\right\rangle}\right)
$$

where $\rho$ is the density of states as a function of energy and $\left\langle E_{\text {Down }}\right\rangle$ is the average energy transferred by downward collisions. Upward collisions are described by elements, $\mathbf{P}_{\mathrm{ji}}$, giving 
the probability that a molecule at energy i will transfer upward to energy $j$ after a collision. The upward transition probabilities are constrained by detailed balance relative to the downward collision probabilities:

$$
\frac{\boldsymbol{P}_{j i}}{\boldsymbol{P}_{i j}} \propto\left(\frac{\rho\left(E_{j}\right)}{\rho\left(E_{i}\right)}\right) \exp \left(\frac{-\left(E_{j}-E_{i}\right)}{k T}\right)
$$

where $\mathrm{k}$ is the Boltzmann constant. Collisions thus establish the thermal (Boltzmann) distribution in the limit of slow reaction (unimolecular decay) relative to the collision frequency. The unimolecular decay rate of Criegee intermediates is determined by the microcanonical rate constant matrix, as defined by the RRKM calculations described above. All calculations were performed with a bath gas temperature of $298 \mathrm{~K}$.

Unimolecular decay of Criegee intermediates to products occurs on both prompt and thermal timescales. Prompt decay of the Criegee intermediate must occur before substantial collisional cooling of activated Criegee intermediates by the bath gas. The collision frequency is $10 \mathrm{~ns}^{-1}(\mathrm{GHz})$ at $1 \mathrm{~atm}$, and many collisions are required for full stabilization, causing thermalization to be complete within 100 ns. The Criegee intermediates that undergo prompt decay mainly come from the highest energy part of the initial Criegee intermediate energy distribution with energies above TS3 and with rate constants $\mathrm{k}(\mathrm{E})>10^{7} \mathrm{~s}^{-1}$. Thermal decay of Criegee intermediates occurs on a much longer timescale ( $\sim 3$ ms at 298 $\mathrm{K})$ and involves Criegee intermediates that have already reached a thermal energy distribution, with the onset of thermal loss beginning after $0.05 \mathrm{~ms}\left(5 \times 10^{-5} \mathrm{~s}\right)$. The large difference in the timescales for prompt and thermal loss means that during the intermediate time period, between $100 \mathrm{~ns}\left(1 \times 10^{-7} \mathrm{~s}\right)$ and $0.05 \mathrm{~ms}$ at $1 \mathrm{~atm}$ and $298 \mathrm{~K}$, there is a steady-state population of the Criegee intermediate. This intermediate time period corresponds to a steady-state balance involving both collisional stabilization and thermal unimolecular decay; it is termed the pseudo steady-state. The two time regimes of prompt and thermal dissociation are manifested in the eigenvalues, $\lambda_{\mathrm{i}}$, which provide the full solution to the master equation. There is a characteristically large separation, often of order $10^{6}$, between the smallest eigenvalue $\lambda_{1}$, and all other $\lambda_{\mathrm{i}}$, which are more similar in magnitude. ${ }^{7,37}$ The eigenvalue $\lambda_{1}$ corresponds to the rate constant for thermal reaction. The pseudo steady-state condition is determined by setting $\lambda_{1}$ to zero prior to calculating the steady state population in $\mathrm{Eq} 4$ and gives the yield of stabilized Criegee intermediates. ${ }^{7}$

Angular momentum was not explicitly taken into account in these calculations. For the synmethyl Criegee intermediate, the microcanonical and thermal decay rates were previously shown to have only a weak dependence on J. ${ }^{36,37}$ For $\left(\mathrm{CH}_{3}\right)_{2} \mathrm{COO}$, the microcanonical decay rate was shown to have an even weaker dependence on angular momentum. ${ }^{36}$

\section{Results and Discussion}

Criegee Intermediate Activation Following TME Ozonolysis

To predict the yields of $\mathrm{OH}$ and stabilized Criegee intermediate from ozonolysis reactions, the energy distribution of the nascent Criegee intermediate must be known. The initial competition between unimolecular decay and collisional stabilization is strongly dependent on the initial chemical activation of the Criegee intermediate, characterized by the average energy and the spread of energies about this average. For higher average energies, the rate of unimolecular decay increases and more collisions are required for stabilization. These effects reduce the fraction of activated Criegee intermediates that can be stabilized. The fraction of stabilized Criegee intermediates formed depends on the rate for collision with bath gas molecules, which depends on pressure, and the rate for unimolecular decay, which depends on the initial chemical 
activation. The initial energy distribution of the Criegee intermediate following ozonolysis is thus directly related to the yield of stabilized Criegee intermediates with varying pressure.

Measurements of the pressure dependence for stabilized Criegee intermediate formation can be used to constrain the initial energy distribution of Criegee intermediates formed from alkene ozonolysis. The timescale for prompt unimolecular decay is orders of magnitude shorter than the timescale for thermal unimolecular decay, so a scavenger needs to undergo bimolecular reaction with Criegee intermediates on a timescale faster than thermal decay. The fraction of Criegee intermediates that react with the scavenger will then correspond to Criegee intermediates that would decay on a thermal timescale, which are stabilized Criegee intermediates. The fraction that does not react with the scavenger is the prompt yield, which can be determined in our master equation modeling by evaluating the pseudo steady state solution.

Experiments probing the pressure dependence of stabilized Criegee intermediate formation following alkene ozonolysis have been performed using a number of scavengers and measurement techniques. 4,8,9,11,63-65 The most recent study for the pressure-dependence of stabilized Criegee intermediate formation from TME ozonolysis used $50 \mathrm{ppm} \mathrm{SO}_{2}$ as a scavenger with mass spectrometric detection of $\mathrm{H}_{2} \mathrm{SO}_{4} \cdot{ }^{9}$ The timescale for the bimolecular reaction at this scavenger concentration is $\sim 5$ us. $^{20,25}$ This is 600 times shorter than the estimated timescale for thermal decay of $\sim 3 \mathrm{~ms}$, so essentially all stabilized Criegee intermediates formed will be scavenged. ${ }^{36,42}$ When $\left(\mathrm{CH}_{3}\right)_{2} \mathrm{COO}$ decomposes it produces $\mathrm{OH}$ radicals, and $\mathrm{SO}_{2}$ will also scavenge these $\mathrm{OH}$ radicals to make $\mathrm{H}_{2} \mathrm{SO}_{4}{ }^{4,9}$ However, a second scavenger (e.g. propane) can be added that selectively reacts with $\mathrm{OH}$ and not the stabilized Criegee intermediate. Provided that the
$\mathrm{OH}$ yield is well known (nearly unity for $\left.\left(\mathrm{CH}_{3}\right)_{2} \mathrm{COO}\right)$, the stabilized Criegee intermediate yield is then given by the ratio of the $\mathrm{H}_{2} \mathrm{SO}_{4}$ signal with and without the $\mathrm{OH}$ scavenger present, independent of any absolute calibration of the $\mathrm{H}_{2} \mathrm{SO}_{4}$. These results are taken to be the most accurate to date, largely because of the high measurement precision and insensitivity to absolute calibration of reactant or product measurements. ${ }^{9}$ We use these new measurements to constrain the initial energy distribution in our master equation modeling and predict stabilized Criegee in-

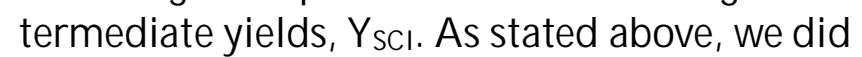
this by solving the master equation using the pseudo steady-state condition to calculate the fraction of chemically activated Criegee intermediates that rapidly decays to products.

We determined the initial energy distribution of the Criegee intermediate by matching calculated stabilized Criegee intermediate yields with the measurements of Hakala and Donahue. $^{9}$ We allocated $18200 \mathrm{~cm}^{-1}$ (52 $\mathrm{kcal} / \mathrm{mol}$ ) to internal (reactive) modes of the reactants and $1450 \mathrm{~cm}^{-1}(4 \mathrm{kcal} / \mathrm{mol})$ to translational (non-reactive) modes. This translates to $2300 \mathrm{~cm}^{-1}$ of the potential energy released after crossing the TS2 barrier to internal energy of the product fragments. Statistical energy partitioning of this internal energy between the Criegee intermediate and the CCP results in an average Criegee intermediate energy of $8500 \mathrm{~cm}^{-1}$. The energy distribution is Gaussian-like, centered at $8500 \mathrm{~cm}^{-1}$ with a full width at half maximum of $6000 \mathrm{~cm}^{-1}$.

Tunneling must be considered when using pressure-dependent $Y_{\text {SCI }}$ to determine the initial energy distribution of chemically activated Criegee intermediates following ozonolysis. Figure 1 clearly shows that a substantial fraction (0.18) of Criegee intermediates are initially formed with energies below the barrier to TS3. If tunneling is neglected, all these Criegee intermediates would be designated as stabilized Criegee intermediates, because the 
rate of unimolecular decay would be zero in this energy range. This zero-pressure intercept of stabilized Criegee intermediate formation has been described as the fraction of Criegee intermediates that are "bom cold" after ozonolysis. ${ }^{17,8}$ As shown in Figure 2, unimolecular decay of the Criegee intermediate does indeed occur at energies significantly below the TS3 barrier. The energy threshold for decay actually lies at ca. $600 \mathrm{~cm}^{-1}$, the asymptotic energy of the $\mathrm{OH}$ and vinoxy products relative to the Criegee intermediate. This low-energy cutoff for reaction means that the full range of Criegee intermediate energies, including energies significantly below the barrier to TS3, determines the timescale for unimolecular decay. At very low pressure the timescale for collisions becomes long, and even Criegee intermediates with energies well below the TS3 barrier have rates for unimolecular decay that are competitive with collisional stabilization. This means that tunneling allows YSCI to be effectively zero at zero pressure, and this is critical in fitting master-equation results to data for $\mathrm{Y}_{\mathrm{SCI}}$ from pressure-dependent scavenging experiments.

We show results for two master-equation models and the recent experimental data for pressure-dependent yields of YSCI $_{\text {in Figure } 3 .}$ Master-equation results with and without tunneling are shown, along with data from Hakala and Donahue. ${ }^{9}$ The master-equation model with tunneling reproduces both the shape and absolute magnitude of the observations. Tunneling must be included to fit the pressure-dependent stabilization measurements, because the measured $Y_{\text {SCI }}$ of 0.13 at 50 torr is less than the fraction of nascent Criegee intermediates with energy below the barrier $\left(5650 \mathrm{~cm}^{-1}\right)$ to unimolecular decay, 0.18 . Without tunneling, all activated Criegee intermediates formed below $5650 \mathrm{~cm}^{-1}$ would necessarily be classified as stabilized Criegee intermediates, and as shown in Fig 3, this results in significant overestimation of $Y_{\text {SCI. }}$.

\section{Contribution of Tunneling to Total Unimolecular Decay}

By influencing the microcanonical rate constants near and below the TS3 zero-point corrected barrier, tunneling plays an important role in the decomposition of Criegee intermediates on the longer, thermal timescale.

We continue to focus on a holistic treatment of Criegee intermediate decomposition following ozonolysis by examining the total reactive flux of Criegee intermediates to $\mathrm{OH}$ products via TS3. The normalized flux, $\phi(E)$, is defined as the fraction of the total population passing to products per unit energy, expressed as a concentration of molecules $\left(\# \mathrm{~cm}^{3}\right)$ per $10 \mathrm{~cm}^{-1}$ per second. It is given by

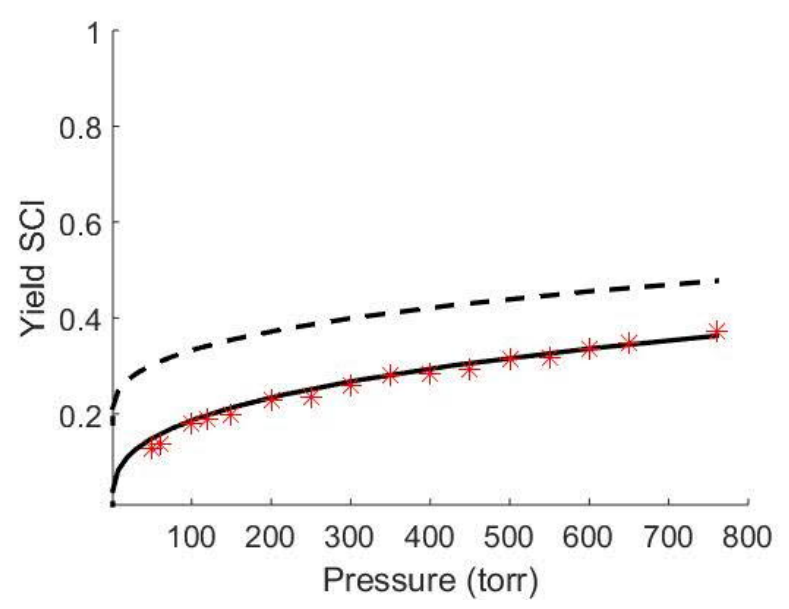

Figure 3. The yield of stabilized Criegee intermediate (Y $\left.\mathrm{Y}_{\text {SCI }}\right)$ following TME ozonolysis as a function of pressure at $298 \mathrm{~K}$. Measurements ${ }^{9}$ are shown as red points. Master-equation calculations are shown including tunneling (solid line) and without including tunneling (dashed line) in unimolecular decay rates.

$$
\varphi_{S S}(E)=N_{S S}(E) k(E)
$$

where $\mathrm{N}_{\mathrm{ss}}$ is the normalized steady-state population calculated from Eq. 4 with thermal decomposition included. 7,1,48 The normalized flux gives the contribution of Criegee intermediates within a given energy range relative to the total Criegee intermediate decomposition. We show these results at 1atm ( 760 torr) pressure in Figure 4 for two cases: without tunneling (left) and including tunneling (right). We plot the normalized flux per $10 \mathrm{~cm}^{-}$ 
${ }^{1}$ increment so that the values on the $\varphi_{s s}(E)$ axis are easy to interpret. The total flux (black) is clearly bimodal, with the highenergy portion (red) corresponding to prompt decomposition and the low-energy portion (blue) corresponding to thermal decomposition. The fluxes for prompt decomposition correspond to the fraction of Criegee intermediates that are not collisionally stabilized (1 SCI $_{\text {SCI }}$, which we calculate using the pseudosteady state condition:

$$
\varphi_{P S S}(E)=N_{P S S}(E) k(E)
$$

Here NPSS is the pseudo steady-state population calculated from Eq. 4 when neglecting thermal decomposition. The maximum value of the thermal flux including tunneling is $1.2 \times 10^{-4}$ per $10 \mathrm{~cm}^{-1}$ interval, and the peak is roughly $5000 \mathrm{~cm}^{-1}$ wide, giving an integrated yield of approximately $0.3 \quad(1 / 2$ base $x$ height); the maximum value of the prompt flux is $1.5 \times 10^{-4}$ per $10 \mathrm{~cm}^{-1}$ interval, and the peak is roughly $10000 \mathrm{~cm}^{-1}$ wide, giving an integrated yield of approximately 0.7 .

The prompt flux resembles the initial energy distribution of the Criegee intermediate, weighted toward higher energy and with a contribution from tunneling at energies in the vicinity of and below the TS3 barrier. The prompt flux corresponds to the Criegee intermediate population that decays to products within 100 ns after formation, and hence this flux occurs from an energy distribution that remains similar to the initial energy distribution. The collision frequency at $1 \mathrm{~atm}$ (760 torr) is about $10^{10} \mathrm{~s}^{-1}(10 \mathrm{GHz})$, and in our model each collision removes on average 250 $\mathrm{cm}^{-1}\left(\left\langle E_{\text {Down }}\right\rangle=250 \mathrm{~cm}^{-1}\right)$ so it takes on average 4 collisions to remove $1000 \mathrm{~cm}^{-1}$ from the chemically activated Criegee intermediates. At high energies, above $9000 \mathrm{~cm}^{-1}$, unimolecular decay is sufficiently fast to occur prior to the chemically activated Criegee intermediate suffering more than a few collisions. The initial Criegee intermediate energy distribution peaks near $8500 \mathrm{~cm}^{-1}$, so a large fraction of
Criegee intermediates fall within this high energy range. At lower energies near the TS3 barrier at $5650 \mathrm{~cm}^{-1}, \mathrm{k}(\mathrm{E})$ is much lower than the collision frequency and almost all of these Criegee intermediates are collisionally stabilized; however, tunneling still has some effect. With tunneling, $\mathrm{k}(\mathrm{E})$ are larger near the TS3 barrier, and a larger fraction of the Criegee intermediate population decays prior to becoming collisionally stabilized. As a result the prompt flux in the no-tunneling model has a slightly narrower span in energy and a smaller contribution to total decay.

Tunneling has a dramatic effect on the thermal flux, which comes from Criegee intermediates that have attained a near thermal (Boltzmann) energy distribution. If the Criegee intermediate were completely stable, then the Criegee intermediate would relax to a Boltzmann distribution after sufficient collisional stabilization; however, decomposition causes the Criegee intermediate population to relax to a "pseudo steady-state" distribution with $\mathrm{N}_{\mathrm{PSS}}(\mathrm{E})$ depleted at any energy with nonzero $\mathrm{k}(\mathrm{E})$. For simplicity we refer to this steady-state distribution as "thermal". The thermal population distribution, $\mathrm{N}_{\text {Thermal }}(\mathrm{E})$, peaks near $1000 \mathrm{~cm}^{-1}$, and much less than $1 \%$ of this population is above $4000 \mathrm{~cm}^{-1}$. The microcanonical rate constants, $\mathrm{k}(\mathrm{E})$, increase dramatically with energy so that the peak in

the thermal flux, given by the product $\mathrm{N}_{\text {Thermal }}(\mathrm{E}) \cdot \mathrm{k}(\mathrm{E})$, is shifted to much higher energies than the peak in the thermal energy distribution alone. The peak in the thermal flux when accounting for tunneling is near $4500 \mathrm{~cm}^{-1}$, which is well above the peak in $\mathrm{N}_{\text {Thermal }}(\mathrm{E})$ but well below the TS3 barrier at $5650 \mathrm{~cm}^{-1}$. Consequently, the large majority of this flux occurs at energies below the TS3 barrier. By contrast, neglecting tunneling causes the flux to be zero below the TS3 barrier. The model neglecting tunneling results in thermal flux occurring only at energies just above the barrier, with a narrow peak near $6000 \mathrm{~cm}^{-1}$. 

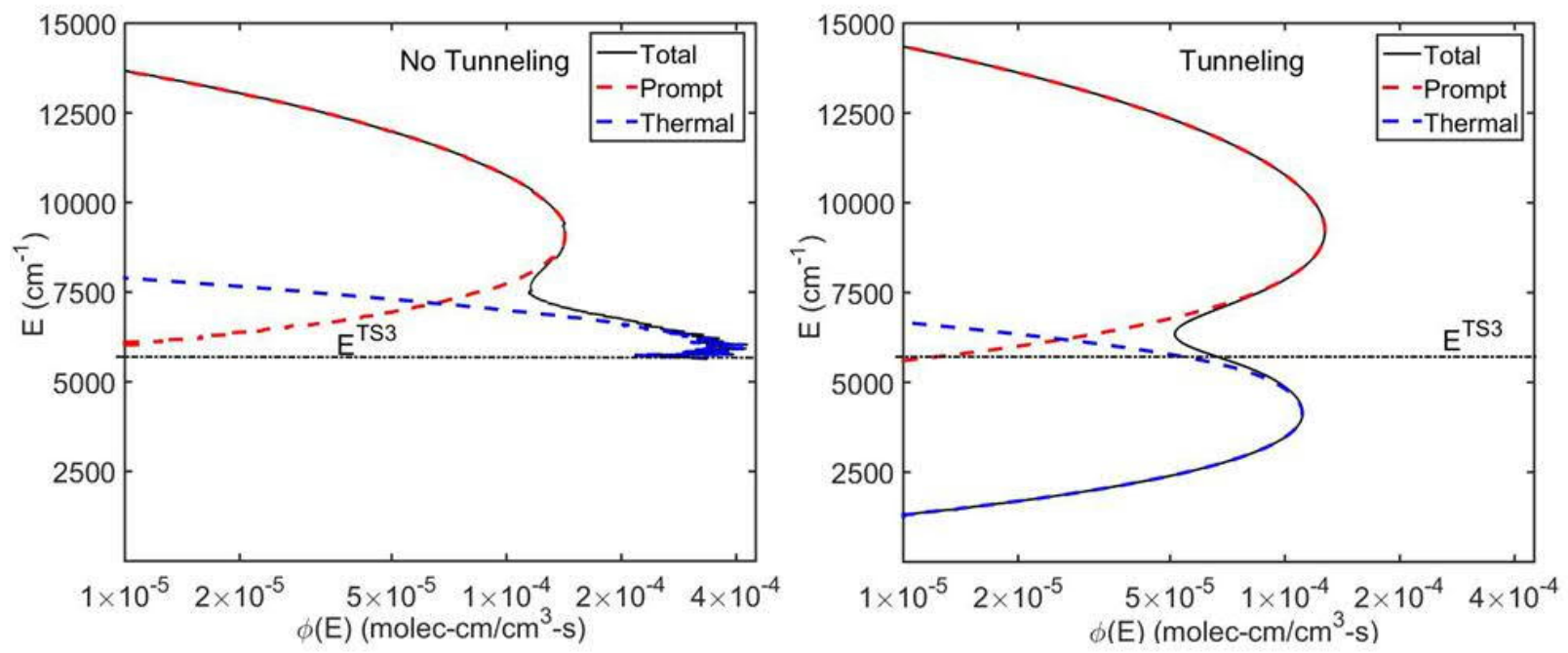

Figure 4. Total (black), prompt (dashed red), and thermal (dashed blue) flux distributions for Criegee intermediate unimolecular decay at atmosphereic conditions (1 atm , $298 \mathrm{~K}$ ) without tunneling (left) and with tunneling calculated using semi-classical transition state theory (SCTST) (right). Tunneling broadens both the prompt and thermal fluxes by increasing $\mathrm{k}(\mathrm{E}) \mathrm{dramatically}$ over a wide range of energies. The prompt flux distributions are largely determined by, and resemble, the initial, chemically activated Criegee intermediate energy distribution following TME ozonolysis.

Thus, thermal decay occurs nearly exclusively by tunneling involving an $\mathrm{H}$-atom transfer that initiates unimolecular decay and $\mathrm{OH}$ formation.

Prompt and Thermal Rates for Unimolecular Decay to $\mathrm{OH}$ Products

The effects of Criegee intermediates in atmospheric oxidation processes are determined by the timescales for prompt and thermal unimolecular decay. We show the yield of $\mathrm{OH}$ products from unimolecular decay of $\left(\mathrm{CH}_{3}\right)_{2} \mathrm{COO}\left(\mathrm{Y}_{\mathrm{OH}}\right)$ as a function of time in Figure 5 (solid black curve) under atmospheric conditions (1 atm, $298 \mathrm{~K})$. For $\left(\mathrm{CH}_{3}\right)_{2} \mathrm{COO}$, and syn-Criegee intermediates in general, unimolecular decay produces $\mathrm{OH}$ with high efficiency. ${ }^{19}$ The timescales for prompt and thermal unimolecular decay are separated by onders of magnitude, and the gap in time between prompt and thermal loss creates a period in which bimolecular reactions can occur, e.g. in scavenger experiments, prior to thermal unimolecular decay. We determined the prompt $\mathrm{OH}$ production from the pseudo steady-state flux by summing the population weighted $\mathrm{k}(\mathrm{E})$ over all energies. This gives an effective rate constant of $10^{9} \mathrm{~s}^{-1}$, which is the microcanonical rate constant near the peak of the nascent energy distribution shown in Figure 1 (red curve). Prompt $\mathrm{OH}$ formation occurs on very short timescales (ns) due to the extreme chemical activation of Criegee intermediates in the initial energy distribution and their corresponding fast $\mathrm{k}(\mathrm{E})$. As we show in Figure 5, within $100 \mathrm{~ns}$, prompt $\mathrm{OH}$ formation is complete, and the prompt $\mathrm{OH}$ yield reaches 0.63. While there are indications of VHP stabilization, 1166 this process is not included in the current study. Thermal $\mathrm{OH}$ production is negligible until 50 us and continues until 30 msec. Our calculated thermal rate constant for $\mathrm{OH}$ production at $298 \mathrm{~K}$ is $340 \mathrm{~s}^{-1}$. This value is good agreement with recent master equation modeling, based on experimentally validated microcanonical rates, which predicts a thermal decay rate of $(\mathrm{CH} 3) 2 \mathrm{COO}$ to $\mathrm{OH}$ products under atmospheric conditions of 276 $\mathrm{S}^{-1}$ at $298 \mathrm{~K}$ (high pressure limit). ${ }^{36,42}$ The thermal unimolecular decay rate of (CH3)2COO has also been studied under la- 
boratory flow cell conditions by Smith et al. and Chhantyal-Pun et al., yielding rates of $36 \pm 49 \mathrm{~s}^{-1}\left(298 \mathrm{~K}, 200\right.$ Torr) and $305 \pm 70 \mathrm{~s}^{-1}$ (293 K, 10-100 Torr), respectively. ${ }^{20,43}$ We also show the thermal $\mathrm{OH}$ yield when tunneling is neglected (dashed-black curve). Without tunneling, the unimolecular decay rate for the Criegee intermediate is $\sim 10 \mathrm{~s}^{-1}$ and $\mathrm{OH}$ production occurs over a period from $1 \mathrm{~ms}$ to $1 \mathrm{~s}$. The time period between prompt $\mathrm{OH}$ production (100 ns) and the onset of thermal $\mathrm{OH}$ production (50 $\mu \mathrm{s})$ is exploited in the scavenger experiments for measuring Y $_{\text {SCI }}$ discussed above. Using current rate-constant measurements, ${ }^{20} 50 \mathrm{ppm}$ of $\mathrm{SO}_{2}$ reacts quickly measurements, ${ }^{20} 50 \mathrm{ppm}$ of $\mathrm{SO}_{2}$ reacts quickly enough to completely react with any stabilized Criegee intermediates formed in TME ozonolysis in laboratory scavenging experiments. Conditions more representative of elevated ambient levels ( $50 \mathrm{ppb} \mathrm{SO}$ ) would have competition between reaction with $\mathrm{SO}_{2}$ and thermal unimolecular decay.

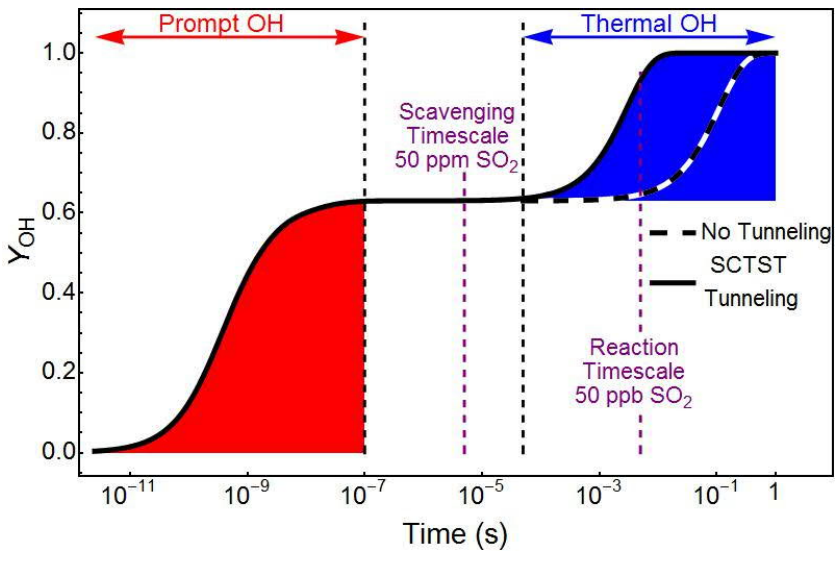

Figure 5. Time dependent yield of $\mathrm{OH}$ (solid black line) under atmospheric conditions ( $1 \mathrm{~atm}, 298 \mathrm{~K})$. Prompt OH production is completed within 100 ns of Criegee intermediate formation, followed by negligible $\mathrm{OH}$ formation until the onset of thermal decay at $50 \mu \mathrm{s}$, when accounting for tunneling. The $50 \mathrm{ppm} \mathrm{SO} \mathrm{S}_{2}$ laboratory scavenger experiments occur on a timescale that enables complete scavenging of stabilized Criegee intermediates. The timescale for reaction with elevated atmospheric levels (50 ppb) of $\mathrm{SO}_{2}$ show unimolecular decay dominates. Neglecting tunneling (dashed, black line) causes the thermal decay to be dramatically slower.

\section{Conclusions and Atmospheric Importance}

Understanding the effects of alkene ozonolysis in the atmosphere requires detailed knowledge of the fate of Criegee intermediates, and this study merges two fields of experimental study, via master equation modeling, to advance our understanding of Criegee intermediates formed from alkene ozonolysis. We combined detailed measurements of microcanonical rate constants and the pressure dependence of stabilized Criegee intermediate formation to create inputs to steady-state master-equation modeling of TME ozonolysis that are consistent with current knowledge of this system. The initial energy distribution of Criegee intermediates formed in alkene ozonolysis is taken to be statistical. Criegee intermediate unimolecular decomposition to radical products occurs on two timescales, prompt $\left(10^{-9} \mathrm{~s}\right)$ and thermal $\left(10^{-3} \mathrm{~s}\right)$. Accounting for tunneling increases prompt $\mathrm{OH}$ production at energies near the TS3 barrier, and thermal $\mathrm{OH}$ production occurs mainly via tunneling. One effect of tunneling is to substantially lower the energy of the vinyl hydroperoxide formed following $\mathrm{H}$-atom transfer under thermal conditions. This will greatly increase the probability of collisional stabilization of VHP. ${ }^{1166}$ It is likely that any stabilized vinyl hydroperoxide would decay rapidly. ${ }^{17,66}$

Both temperature and the structure (size/conformation) of Criegee intermediates need to be considered when applying laboratory measurements and kinetics modeling in atmospheric models, because both affect the competition between unimolecular decay and bimolecular reaction. This is particularly important when considering the range of Criegee intermediates that are formed from the wide variety of alkenes in the ambient atmosphere. Measurements are currently not available for Criegee intermediates with more than 3 carbons or with functional groups other than alkyl chains, such as the 5 carbon unsaturated Criegee intermediate that would form in isoprene ozonolysis. For bimolecular reactions to 
compete with thermal unimolecular decay for $\left(\mathrm{CH}_{3}\right)_{2} \mathrm{COO}$, the reactions need to occur on a timescale of a few ms or less; even if these reactions occur at the collisional rate constant of $3 \times 10^{-10} \mathrm{~cm}^{3}$ molec $^{-1} \mathrm{~s}^{-1}$, the mole fraction of the co-reactant would need to be at least $100 \mathrm{ppb}$. However, the thermal rate constant for unimolecular decay is strongly temperature dependent, ${ }^{36,42}$ so at reduced temperatures bimolecular reactions could be more competitive. Also, larger Criegee intermediates with more internal modes than $\left(\mathrm{CH}_{3}\right)_{2} \mathrm{COO}$ will have correspondingly longer lifetimes for prompt unimolecular decay, analogous to observed decreases in microcanonical decay rates when comparing $\mathrm{CH}_{3} \mathrm{CHOO}$, $\left(\mathrm{CH}_{3}\right)_{2} \mathrm{COO}$, and $\mathrm{CH}_{3} \mathrm{CH}_{2} \mathrm{CHOO} .35,36,42,46$ Thermal decay rates are not expected to change dramatically because the transition state and reactant canonical partition functions change similarly with added degrees of freedom. ${ }^{36,42}$

Our master-equation modeling results, in agreement with current measurements of Criegee intermediate bimolecular reactions, $20,24,25,36$ show that thermal unimolecular decay will be the dominant loss process for $\left(\mathrm{CH}_{3}\right)_{2} \mathrm{COO}$ in the atmosphere. Figure 5 shows that thermal decay of stabilized Criegee intermediates nears completion faster than the timescale for reaction with $\mathrm{SO}_{2}$ at concentrations that are high for the atmosphere (50 ppb). While unimolecular decay will dominate Criegee intermediate behavior, reaction with $\mathrm{SO}_{2}$ can still occur; results from a recent field-study suggest that oxidation of $\mathrm{SO}_{2}$ by stabilized Criegee intermediates may account for up to half of sulfuric acid production in some forested areas. ${ }^{38}$ Modeling of Criegee intermediates in the atmosphere suggests the potential importance on $\mathrm{H}_{2} \mathrm{SO}_{4}$ formation and particle nucleation, though aerosol microphysics may result in small impacts on formation of cloud condensation nuclei. ${ }^{67}$ As noted above, the reactivity of larger stabi- lized Criegee intermediates that are present in the atmosphere has yet to be directly observed, and future measurements for larger Criegee intermediates, such as those from isoprene, are needed for incorporation into atmospheric models. By combining current experimental data through master-equation modeling, we guide the way for future kinetic modeling of larger Criegee intermediates using computational methods.

\section{AUTHOR INFORMATION}

\section{Corresponding Author}

*milester@sas.upenn.edu

\section{Acknowledgements}

The research at the University of Pennsylvania was supported through the National Science Foundation under grant CHE1362835 (MIL). NMD acknowledges funding from NASA (Grant NNX12AE54G). TK thanks the Academy of Finland (266388) for funding, and the CSC IT Center for Science in Espoo, Finland, for computing time.

\section{REFERENCES}

(1) Donahue, N. M.; Drozd, G. T.; Epstein, S. A.; Presto, A. A.; Kroll, J. H. Adventures in Ozoneland: Down the RabbitHole. Phys. Chem. Chem. Phys. 2011, 13 (23), 10848- 10857. Johnson, D.; Marston, G. The Gas-Phase Ozonolysis of Unsaturated Volatile Organic Compounds in the Troposphere. Chem. Soc. Rev. 2008, 37, 699-716.

(3) Donahue, N. M.; Kroll, H.; Anderson, J. G.; Demerjian, K. L. Direct Observation of $\mathrm{OH}$ Production from the Ozonolysis of Olefins. Geophys. Res. Lett. 1998, 25 (1), 59-62.

(4) Berndt, T.; Jokinen, T.; Sipilä, M.; Mauldin, R. L.; Herrmann, H.; Stratmann, F.; Junninen, H.; Kulmala, M. $\mathrm{H}_{2} \mathrm{SO}_{4}$ Formation from the Gas-Phase Reaction of Stabilized Criegee Intermediates with $\mathrm{SO}_{2}$ : Influence of Water Vapour Content and Temperature. Atmos. Environ. 2014, 89, 603-612.

(5) Ehn, M.; Thornton, J. A.; Kleist, E.; Sipila, M.; Junninen, H.; Pullinen, I.; Springer, M.; Rubach, F.; Tillmann, R.; Lee, B.; et al. A Large Source of Low-Volatility Secondary Organic Aerosol. Nature 2014, 506, 476-479.

(6) Jokinen, T.; Berndt, T.; Makkonen, R; Kerminen, V.-M.; Junninen, H.; Paasonen, P.; Stratmann, F.; Herrmann, H.; Guenther, A. B.; Worsnop, D. R.; et al. Production of Extremely Low Volatile Organic Compounds from Biogenic Emissions: Measured Yields and Atmospheric Implications. Proc. Natl. Acad. Sci. U. S. A. 2015, 112 (23), 7123-7128.

(7) Kroll, J. H.; Sahay, S. R.; Anderson, J. G.; Demerjian, K. L. Donahue, N. M. Mechanism of HOx Formation in the GasPhase Ozone-Alkene Reaction. 2. Prompt versus Thermal Dissociation of Carbonyl Oxides to Form OH. J. Phys. Chem. A 2001, 105 ( 18), 4446-4457.

(8) Drozd, G. T.; Donahue, N. M. Pressure Dependence of Stabilized Criegee Intermediate Formation from a Sequence of Alkenes. J. Phys. Chem. A 2011, 115 (17), 4381-4387.

(9) Hakala, J. P.; Donahue, N. M. Pressure-Dependent Criegee 
Intermediate Stabilization from Alkene Ozonolysis. J. Phys. Chem. A 2016, 120 (14), 2173-2178.

(10) Osborn, D. L.; Taatjes, C. A. The Physical Chemistry of Criegee Intermediates in the Gas Phase. Int. Rev. Phys. Chem. 2015, 34 (3), 309-360.

(11) Drozd, G. T. G. T.; Kroll, J.; Donahue, N. M. N. M. 2,3 Dimethyl-2-Butene (TME) Ozonolysis: Pressure Dependence of Stabilized Criegee Intermediates and Evidence of Stabilized Vinyl Hydroperoxides. J. Phys. Chem. A 2011, 115 (2), 161-166.

(1) Anglada, J. M.; Bofill, J. M.; Olivella, S.; Solé, A. Unimolecular Isomerizations and Oxygen Atom Loss in Formaldehyde and Acetaldehyde Carbonyl Oxides. A Theoretical Investigation. J. Am. Chem. Soc. 1996, 118 (19), 4636-4647.

(13) Kroll, J. H.; Donahue, N. M.; Cee, V. J.; Demerjian, K. L.; Anderson, J. G. Gas-Phase Ozonolysis of Alkenes: Formation of $\mathrm{OH}$ from Anti Carbonyl Oxides. J. Am. Chem. Soc. 2002, 124 (29), 8518-8519.

(4) Olzmann, M.; Kraka, E; Cremer, D.; Gutbrod, R.; Andersson, S.; Olzmann, M.; Kraka, E; Cremer, D.; Gutbrod, R.; Andersson, S.; et al. Energetics, Kinetics, and Product Distributions of the Reactions of Ozone with Ethene and 2,3-Dimethyl-2-Butene. J. Phys. Chem. A 1997, 101(49), 9421-9429.

(15) Womack, C. C.; Martin-Drumel, M.-A.; Brown, G. G.; Field, R. W.; McCarthy, M. C. Observation of the Simplest Criegee Intermediate $\mathrm{CH}_{2} \mathrm{OO}$ in the Gas-Phase Ozonolysis of Ethylene. Sci. Adv. 2015, 1(2), 1400105-1400111.

(16) Nguyen, T. L.; Lee, H.; Matthews, D. A.; McCarthy, M. C.; Stanton, J. F. Stabilization of the Simplest Criegee Intermediate from the Reaction between Ozone and Ethylene: A High-Level Quantum Chemical and Kinetic Analysis of Ozonolysis. J. Phys. Chem. A 2015, 119 (22), 55245533.

(17) Taatjes, C. A.; Liu, F.; Rotavera, B.; Kumar, M.; Caravan, R.; Osborn, D. L; Thompson, W. H.; Lester, M. I. Hydroxyacetone Production From $\mathrm{C}_{3}$ Criegee Intermediates. J. Phys. Chem. A 2016, 121, 16-23.

(18) IUPAC Subcommittee on Gas Kinetic Data Evaluation. Data Sheet Ox VOC3. http://iupac.poleether.fr/htdocs/datasheets/pdf/Ox_VOC3_O3_alkene.pdf. 2005.

(19) Welz, O.; Savee, J. D.; Osborn, D. L.; Vasu, S. S.; Percival, C. J.; Shallcross, D. E.; Taatjes, C. A. Direct Kinetic Measurements of Criegee Intermediate $\left(\mathrm{CH}_{2} \mathrm{OO}\right)$ Formed by Reaction of $\mathrm{CH}_{2} \mathrm{I}$ with $\mathrm{O}_{2}$. Science 2012, 335 (6065), 204207.

(20) Chhantyal-Pun, R.; Welz, O.; Savee, J. D.; Eskola, A. J.; Lee, E. P. F.; Blacker, L.; Hill, H. R.; Ashcroft, M.; Khan, M. A. H. H.; Lloyd-Jones, G. C.; et al. Direct Measurements of Unimolecular and Bimolecular Reaction Kinetics of the Criegee Intermediate (CH3)2COO. J. Phys. Chem. A 2017, 121, 4-15.

(21) Taatjes, C. A.; Shallcross, D. E.; Percival, C. J. Research Frontiers in the Chemistry of Criegee Intermediates and Tropospheric Ozonolysis. Phys. Chem. Chem. Phys. 2014, 16 (5), 1704-1718.

(22) Chao, W.; Hsieh, J.-T.; Chang, C.-H.; Lin, J. J.-M. Direct Kinetic Measurement of the Reaction of the Simplest Criegee Intermediate with Water Vapor. Science 2015, 347 (6223), $751-754$.

(23) Lewis, T. R.; Blitz, M. A.; Heard, D. E.; Seakins, P. W. Direct Evidence for a Substantive Reaction between the Criegee Intermediate, $\mathrm{CH}_{2} \mathrm{OO}$, and the Water Vapour Dimer. Phys. Chem. Chem. Phys. 2015, 17 (7), 4859-4863.

(24) Lee, Y.-P. Perspective: Spectroscopy and Kinetics of Small Gaseous Criegee Intermediates. J. Chem. Phys. 2015, 143 (2),

20901

Huang, H. L.; Chao, W.; Lin, J. J. Kinetics of a Criegee Intermediate That Would Survive High Humidity and May Oxidize Atmospheric $\mathrm{SO}_{2}$. Proc. Natl. Acad. Sci. U.S.A. 2015, 112 (35), 10857-10862.

Vereecken, L; Harder, H.; Novelli, A. The Reaction of Criegee Intermediates with $\mathrm{NO}, \mathrm{RO} 2$, and $\mathrm{SO} 2$, and Their Fate in the Atmosphere. Phys. Chem. Chem. Phys. 2012, 14 (4), 4682-14695.

Kurten, T.; Lane, J. R.; Jørgensen, S.; Kjaergaard, H. G. A Computational Study of the Oxidation of $\mathrm{SO}_{2}$ to $\mathrm{SO}_{3}$ by Gas-Phase Organic Oxidants. J. Phys. Chem. A 2011, 115, 8669-8681.

Kuwata, K. T.; Guinn, E. J.; Hermes, M. R; Fernandez, J. A.; Mathison, J. M.; Huang, K. A Computational ReExamination of the Criegee Intermediate-Sulfur Dioxide Reaction. J. Phys. Chem. A 2015, 119 (41), 10316- 10335.

Long, B.; Bao, J. L.; Truhlar, D. G.; Society, A. C. Atmospheric Chemistry of Criegee Intermediates: Unimolecular Reactions and Reactions with Water. J. Am. Chem. Soc. 2016, 138 (43), 14409-14422.

Lin, L.-C.; Chao, W.; Chang, C.-H.; Takahashi, K; Lin, J. J. Temperature Dependence of the Anti-CH3CHOO Reaction with Water Vapor. Phys. Chem. Chem. Phys. 2016, 18, 28189. Taatjes, C. A.; Welz, O.; Eskola, A. J.; Savee, J. D.; Scheer, A. M.; Shallcross, D. E; Rotavera, B.; Lee, E. P. F.; Dyke, J. M.; Mok, D. K. W.; et al. Direct Measurements of ConformerDependent Reactivity of the Criegee Intermediate $\mathrm{CH}_{3} \mathrm{CHOO}$. Science (80-. ). 2013, 340, 177-180.

Welz, O.; Eskola, A. J.; Sheps, L.; Rotavera, B.; Savee, J. D.; Scheer, A. M.; Osborn, D. L; Lowe, D.; Murray Booth, A.; Xiao, P.; et al. Rate Coefficients of $\mathrm{C} 1$ and $\mathrm{C} 2$ Criegee Intermediate Reactions with Formic and Acetic Acid near the Collision Limit: Direct Kinetics Measurements and Atmospheric Implications. Angew. Chemie - Int. Ed. 2014, 53 (18), 4547-4550.

Stone, D.; Blitz, M.; Daubney, L.; Howes, N. U. M.; Seakins, P. Kinetics of $\mathrm{CH}_{2} \mathrm{OO}$ Reactions with $\mathrm{SO}_{2}, \mathrm{NO}_{2}, \mathrm{NO}, \mathrm{H}_{2} \mathrm{O}$ and $\mathrm{CH}_{3} \mathrm{CHO}$ as a Function of Pressure. Phys. Chem. Chem. Phys 2014, 16 (16), 1139-1149.

Anglada, J. M.; Solé, A. Impact of the Water Dimer on the Atmospheric Reactivity of Carbonyl Oxides. Phys. Chem. Chem. Phys. 2016, 18 (26), 17698-17712.

Fang, Y.; Liu, F.; Barber, V. P.; Klippenstein, S. J.; McCoy, A. B.; Lester, M. I. Deep Tunneling in the Unimolecular Decay of $\mathrm{CH}_{3} \mathrm{CHOO}$ Criegee Intermediates to $\mathrm{OH}$ Radical Products. J. Chem. Phys. 2016, 145 (23), 234308.

Fang, Y.; Liu, F.; Barber, V. P.; Klippenstein, S. J.; McCoy, A. B.; Lester, M. I. Real Time Observation of Unimolecular Decay of Criegee Intermediates to OH Radical Products. J. Chem. Phys. 2016, 144 (6), 061101-061106.

Nguyen, T. L.; McCaslin, L.; McCarthy, M. C.; Stanton, J. F. Communication: Thermal Unimolecular Decomposition of Syn-CH3CHOO: A Kinetic Study. J. Chem. Phys. 2016, 145 (13), 10991836.

Mauldin III, R. L.; Berndt, T.; Sipilä, M.; Paasonen, P.; Petäjä, T.; Kim, S.; Kurtén, T.; Stratmann, F.; Kerminen, V.M.; Kulmala, M. A New Atmospherically Relevant Oxidant of Sulphur Dioxide. Nature 2012, 488, 193-197.

Percival, C. J.; Welz, O.; Eskola, A. J.; Savee, J. D.; Osborn, D. L; Topping, D. O.; Lowe, D.; Utembe, S. R.; Bacak, A.; McFiggans, G.; et al. Regional and Global Impacts of Criegee Intermediates on Atmospheric Sulphuric Acid Concentrations and First Steps of Aerosol Formation. Faraday Discuss. 2013, 165, 45.

Kroll, J. H.; Hanisco, T. F.; Donahue, N. M.; Demerjian, K. L; Anderson, J. G. Accurate, Direct Measurements of Oh Yields from Gas-Phase Ozone-Alkene Reactions Using an in 
Situ LIF Instrument. Geophys. Res. Lett. 2001, 28 (20), 38633866.

Orzechowska, G. E; Paulson, S. E. Production of $\mathrm{OH}$ Radicals from the Reactions of $\mathrm{C}_{4}-\mathrm{C}_{6}$ Internal Alkenes and Styrenes with Ozone in the Gas Phase. Atmos. Environ. 2002, 36 (3), 571-581

(42) Fang, Y.; Barber, V. P.; Klippenstein, S. J.; McCoy, A. B.; Lester, M. I. Tunneling Effects in the Unimolecular Decay of (CH3)2COO Criegee Intermediates to $\mathrm{OH}$ Radical Products. J. Chem. Phys. 2017, 146, 134307.

(43) Smith, M. C.; Chao, W.; Takahashi, K.; Boering, K. A.; Lin, J. J. M. Unimolecular Decomposition Rate of the Criegee Intermediate $\left(\mathrm{CH}_{3}\right)_{2} \mathrm{COO}$ Measured Directly with UV Absorption Spectroscopy. J. Phys. Chem. A 2016, 120 (27), 4789-4798.

(44) Kuwata, K. T.; Hermes, M. R.; Carlson, M. J.; Zogg, C. K. Computational Studies of the Isomerization and Hydration Reactions of Acetaldehyde Oxide and Methyl Vinyl Carbonyl Oxide. J. Phys. Chem. A 2010, 114 (34), 9192-9204.

(45) Liu, F.; Beames, J. M.; Lester, M. I. Direct Production of OH Radicals upon $\mathrm{CH}$ Overtone Activation of (CH3)2COO Criegee Intermediates. J Chem. Phys. 2014, 141, 23431.

(46) Fang, Y.; Liu, F.; Klippenstein, S. J.; Lester, M. I. Direct Observation of Unimolecular Decay of $\mathrm{CH}_{3} \mathrm{CH}_{2} \mathrm{CHOO}$ Criegee Intermediates to $\mathrm{OH}$ Radical Products. J. Chem. Phys. 2016, 145 (4), 44312.

(47) Liu, F.; Beames, J. M.; Petit, A. S.; Mccoy, A. B.; Lester, M. I. Infrared-Driven Unimolecular Reaction of $\mathrm{CH} 3 \mathrm{CHOO}$ Criegee Intermediates to $\mathrm{OH}$ Radical Products. Science 2014, 345 (6204), 1596-1598.

(48) Chuong, B.; Zhang, J.; Donahue, N. M. Cycloalkene Ozonolysis: Collisionally Mediated Mechanistic Branching. J. Am. Chem. Soc. 2004, 126 (39), 12363-12373.

(49) Spartan. Spartan 14. Spartan 14. Wavefunction Inc. Irvine CA. 2014.

(50) Frisch, M. J.; Trucks, G. W.; Schlegel, H. B.; Scuseria, G. E.; Robb, M. A.; Cheeseman, J. R.; Scalmani, G.; Barone, V.; Mennucci, B.; Petersson, G. A. . et al. Gaussian 09. Gaussian 09, Revision D.01; Gaussian, Inc.: W allingford, CT, 2009.

(51) Werner, H.-J.; Knowles, P. J.; Knizia, G.; Manby, F. R.; Schütz, M.; Celani, P.; Korona, T.; Lindh, R; Mitrushenkov, A.; Rauhut, G.; et al. MOLPRO. Molpro version 2012.1, a package of ab initio programs, 2012; see http:// www.molpro.net.

(52) Barker, J. R.; Nguyen, T. L.; Stanton, J. F.; Aieta, C.; Ceotto, M.; Gabas, F.; Kumar, T. J. D.; Li, C. G. L; Lohr, L. L; Maranzana, A.; et al. MultiW ell-2017 Software Suite. J. R. Barker, University of Michigan, Ann Arbor, Michigan, USA, Http://clasp-Research.engin.umich.edu/multiwell/; 2017.

(53) Miller, W. H. Semiclassical Limit of Quantum Mechanical Transition State Theory for Nonseparable Systems. J. Chem. Phys. 1975, 62 (5), 1899.

(54) Miller, W. H. Tunneling Corrections to Unimolecular Rate Constants, with Application to Formaldehyde. J. Am. Chem. Soc. 1979, 101(23), 6810-6814.

(55) Forst, W. Theory of Unimolecular Reactions; Academic Press: New York, 1973.

(56) Nguyen, T. L.; Peeters, J.; Vereecken, L. Theoretical Study of the Gas-Phase Ozonolysis of B -Pinene. Phys. Chem. Chem. Phys 2009, 11, 5643-5656.

(57) Vayner, G.; Addepalli, S. V.; Song, K.; Hase, W. L. PostTransition State Dynamics for Propene Ozonolysis: Intramolecular and Unimolecular Dynamics of Molozonide. J. Chem. Phys. 2006, 125 (1), 14317.

(58) Mordaunt, D. H.; Osborn, D. L.; Neumark, D. M. Nonstatistical Unimolecular Dissociation over a Barrier. 1998, 108 (6), 2448.

(59) Levine, R. D.; Bernstein, R. B. Molecular Reaction Dynamics and Chemical Reactivity; Oxford University Pres: New York, NY, USA, 1987.

(60) Hoare, M. Steady-State Unimolecular Processes in Multilevel Systems. J. Chem. Phys. 1963, 38 (7), 1630.

(61) Zhang, J.; Donahue, N. M. Constraining the Mechanism and Kinetics of $\mathrm{OH}+\mathrm{NO}_{2}$ and $\mathrm{HO}_{2}+\mathrm{NO}$ Using the MultipleWell Master Equation. J. Phys. Chem. A 2006, 110 (21), 6898-6911

(62) Serauskas, R. V.; Schlag, E. W. Analysis of Relaxation Processes in a Multilevel System. A Many-Shot Expansion Technique. J. Chem. Phys. 1965, 42 (9), 3009.

(63) Berndt, T.; Jokinen, T.; Mauldin, R. L; Petäjä, T.; Herrmann, H.; Junninen, H.; Paasonen, P.; Worsnop, D. R; Sipilä, M. Gas-Phase Ozonolysis of Selected Olefins: The Yield of Stabilized Criegee Intermediate and the Reactivity toward $\mathrm{SO}_{2}$. J. Phys. Chem. Lett. 2012, 3 (19), 2892-2896.

(64) Presto, A. A.; Donahue, N. M. Ozonolysis Fragment Quenching by Nitrate Formation: The Pressure Dependence of Prompt OH Radical Formation. J. Phys. Chem. A 2004, 108 (42), 9096-9104.

(65) Fenske, J. D.; Hasson, A. S.; Paulson, S. E.; Kuwata, K. T.; Ho, A.; Houk, K. N. The Pressure Dependence of the $\mathrm{OH}$ Radical Yield from Ozone-Alkene Reactions. J. Phys. Chem. A 2000, 104 (31), 7821-7833.

(66) Kurtén, T.; Donahue, N. M. MRCISD Studies of the Dissociation of Vinylhydroperoxide, $\mathrm{CH}_{2} \mathrm{CHOOH}$ : There Is a Saddle Point. J. Phys. Chem. A 2012, 116 (25), 6823-6830.

(67) Pierce, J. R.; Evans, M. J.; Scott, C. E.; D’Andrea, S. D.; Farmer, D. K.; Swietlicki, E.; Spracklen, D. V. Weak Global Sensitivity of Cloud Condensation Nuclei and the Aerosol Indirect Effect to Criegee $+\mathrm{SO}_{2}$ Chemistry. Atmos. Chem. Phys. 2013, 13 (6), 3163-3176. 


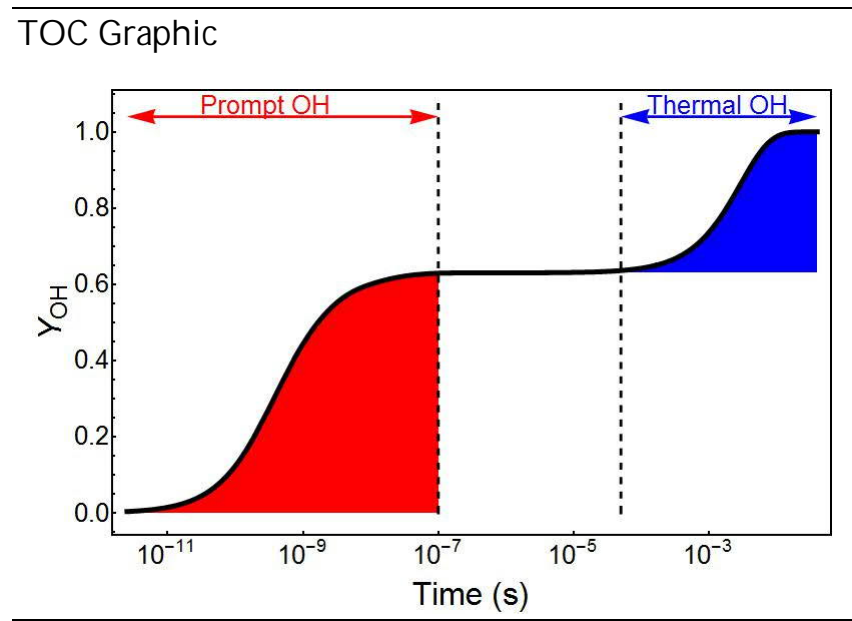

